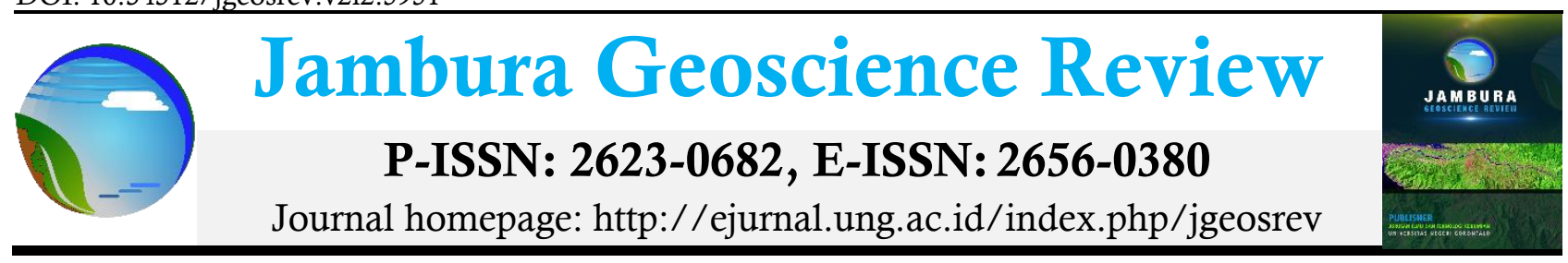

\title{
ESTIMASI PERUBAHAN KUALITAS UDARA BERBASIS CITRA SATELIT PENGINDERAAN JAUH DI SEKITAR PLTU CIREBON
}

\author{
Moh. Dede ${ }^{a}$, Millary Agung Widiawaty ${ }^{b}$, Nurhanifah $^{b}$, Arif Ismail ${ }^{b}$, Ajeng Randhita P. Artati ${ }^{a}$ \\ Amniar Ati ${ }^{\mathrm{d}}$, Yanuar Rizky Ramadhan ${ }^{\mathrm{c}}$ \\ a Program Studi Magister Ilmu Lingkungan, SPs, Universitas Padjadjaran, Jalan Sekeloa No. 01, Kota Bandung, Jawa \\ Barat, Indonesia (40134) \\ ${ }^{b}$ Departemen Pendidikan Geografi, FPIPS, Universitas Pendidikan Indonesia, Jalan Dr. Setiabudhi No. 229, Kota Bandung, \\ Jawa Barat, Indonesia (40151) \\ ${ }^{c}$ Program Studi Meteorologi, FITB, Institut Teknologi Bandung, Jalan Ganesha No. 10, Kota Bandung, Indonesia (40132) \\ ${ }^{d}$ Program Studi Pendidikan Geografi, FKIP, Universitas Halu Oleo, Kampus Hijau Bumi Tridharma, Kota Kendari, \\ Sulawesi Tenggara, Indonesia (93232)
}

\section{ARTICLE INFO}

\section{Article history:}

Received: 6 May 2020

Accepted: 14 June 2020

Available Online: 10 July 2020

\section{Keywords:}

Air quality; Cirebon; Remote Sensing; Satellite Imagery; Steam Power Plant

\section{Corresponding author:}

Moh. Dede

Universitas Padjadjaran, Kota Bandung,

Jawa Barat, Indonesia

Email: m.dede.geo@gmail.com

\begin{abstract}
Steam power plant construction and operation is an effort to meet electricity needs. In Indonesia, two steam power plants were built and changed the landscape in Cirebon. The presence of Cirebon steam power plants has disturbed the community and potential to decrease air quality. This study aims to estimate air quality changes around the power plants based on remote sensing satellite imageries. The main data in this study obtained from Landsat-8 OLI (2019) and Landsat-7 ETM (2004) satellite imageries were processed with four parameters of air quality algorithm namely $\mathrm{PM}_{10}, \mathrm{CO}, \mathrm{SO}_{2}$, and $\mathrm{NO}_{x}$ on $\mathrm{AOI}$ with ranging of $2000 \mathrm{~m}$ from the source point. Validation uses comparative data from MODIS and Sentinel-2 MSS satellite imageries in the same period. Changes analysis in air quality used the Mann-Whitney method (U-Test). This research shows that the Landsat series satellite imagery is suitable to be used as the main data for estimating air quality because it has a similar pattern to comparable data. The Cirebon PLTU operation caused a significant increase in $\mathrm{CO}$ levels of $1.25 \mathrm{mg} / 1$ on a wide range. In other air quality parameters such as $\mathrm{PM}_{10}, \mathrm{SO}_{2}$ and $\mathrm{NO}_{\mathrm{x}}$ were decreased.
\end{abstract}

Copyright $(2020$ JGEOSREV-UNG This open access article is distributed under a Creative Commons Attribution (CC-BY) 4.0 International license

\section{Pendahuluan}

Kebutuhan energi listrik di Indonesia terus meningkat seiring dengan laju pertumbuhan penduduk, industrialisasi, dan perkembangan gaya hidup modern. Energi listrik sebagai salah satu penyokong pembangunan memerlukan kehadiran instalasi pembangkit yang berasal dari berbagai sumber baik yang bersifat renewable maupun unrenewable resources, karena energi merupakan entitas yang tidak dapat diciptakan dan dimusnahkan, dimana pemerolehan sesungguhnya hanyalah bentuk perubahannya semata (Suriamiharja, 2008). Efisiensi perubahan energi diketahui dari nilai entropi yang meliputi luaran daya listrik pembangkit, kalor yang terlepas ke lingkungan, serta beragam limbah yang dihasilkannya (Cahyadi, 2015; ICEL, 2018). Meskipun memiliki banyak sumber daya untuk diubah menjadi energi listrik, pemerintah Indonesia lebih memilih menggunakan batubara dalam rangka pemenuhan rasio elektrifikasi 99,9 persen pada tahun 2020 sebagai bagian dari proyek 35.000 megawatt hingga tahun 2028 (Untsa, 2017; ICED, 2018).

Batubara merupakan bahan bakar untuk mendidihkan uap agar mampu menggerakkan turbin pembangkit listrik tenaga uap (PLTU). Selain menciptakan pangsa pasar batu bara dalam negeri, PLTU dipilih karena lebih mudah untuk dibangun dan dapat ditempatkan lebih dekat dengan 
pengguna yang menyebabkan biaya produksi relatif lebih murah (Cahyadi, 2011). Pembangunan PLTU seakan menjadi solusi jitu untuk memenuhi kebutuhan energi listrik, padahal secara operasional PLTU jangka panjang turut memberikan dampak lingkungan yang akan berimplikasi terhadap kondisi sosialekonomi di sekitarnya (Quina \& Erou, 2018; Julianti et al., 2018) Salah satu operasional pembangkit listrik dengan energi batubara yang turut mengubah kualitas lingkungan dan menjadi perhatian hingga skala nasional adalah PLTU Cirebon yang saat ini memiliki dua unit pembangkit.

PLTU Cirebon menyediakan energi listrik sebesar 600 dan 1000 megawatt bagi penduduk Pulau Jawa (Dewanto, 2016). Meski diklaim sebagai pelopor teknologi batubara bersih, pembangunan dan operasional PLTU di dekat pantai turut mengubah morfologi pesisir dan lingkungan sekitarnya yang memicu reaksi dari masyarakat baik yang berdampak pada tanah, air, maupun udara (Nurhasanah, 2017). Salah satu cara untuk mengetahui perubahan kualitas udara yakni melalui pemanfaatan citra satelit penginderaan jauh sebagai bagian dari monitoring lingkungan. Citra satelit penginderaan jauh multi-spektral memiliki beberapa sensor yang dapat disesuaikan dengan kebutuhan monitoring lingkungan oleh pengguna serta memiliki skala spasial dan waktu perekaman yang luas (Nguyen et al., 2015; Matharaarachchi et al., 2016; Martin, 2008). Estimasi beberapa indikator kualitas udara melalui pemanfaatan citra satelit penginderaan jauh yang meliputi suhu, kelembapan udara, $\mathrm{PM}_{2.5}$, dan $\mathrm{PM}_{10}$ (Martin, 2008; Matharaarachchi et al., 2016; Nguyen et al., 2015). Bahkan dapat pula untuk mengamati perubahan konsentrasi gas rumah kaca seperti $\mathrm{CO}, \mathrm{SO}_{2}, \mathrm{NO}_{\mathrm{x}}, \mathrm{O}_{3}$, dan black particulates (BP) (Wald et al., 1998). Citra satelit penginderaan jauh yang lazim dimanfaatkan untuk monitoring perubahan kualitas udara yakni MODIS, Landsat, dan Sentinel. Menurut Lin et al. (2019, citra satelit penginderaan jauh bukan hanya mampu memberikan informasi terkait perubahan kualitas udara, melainkan menyajikan variasi spasial-temporal yang dapat dipadukan dengan data pengukuran lapangan dengan hasil memuaskan. Pada parameter gas rumah kaca, data dari citra satelit penginderaan jauh memiliki korelasi dengan hasil pengukuran yang signifikan dengan $\mathrm{R}^{2}$ sebesar 0,52 (Hasan et al., 2014). Hal yang serupa juga terjadi pada pengukuran parameter material padat pengotor udara dengan $\mathrm{R}^{2}$ sebesar 0,68 hingga 0,94 (Nicolantonio et al., 2009; Fernández-Pacheco et al., 2018).

Informasi mengenai perubahan kualitas udara akibat kedua PLTU Cirebon pernah dilakukan oleh Muhaimin et al., (2016) berdasarkan simulasi menggunakan model Gaussian plume yang menyatakan bahwa kadar maksimum $\mathrm{SO}_{x}$ sebesar $52,95 \mu \mathrm{g} / \mathrm{m}^{3}$ dan $\mathrm{NO}_{\mathrm{x}}$ sebesar $44,86 \mu \mathrm{g} / \mathrm{m}^{3}$ - lebih rendah dari baku mutu maksimum. Di sisi lain, operasional pembangkit tersebut menyebabkan sebagian warga mengalami infeksi saluran pernapasan atas (ISPA) (Nurhasanah, 2017). Berdasarkan uraian tersebut, penelitian ini bertujuan untuk menganalisis perubahan kualitas udara berbasis citra satelit penginderaan jauh di sekitar PLTU Cirebon, sekaligus menyikapi dualisme hasil dari dua penelitian sebelumnya. Pada kajian ini tidak semua parameter kualitas udara digunakan, tetapi terbatas pada $\mathrm{PM}_{10}, \mathrm{CO}, \mathrm{SO}_{2}$, serta $\mathrm{NO}_{\mathrm{x}}$. Untuk menguji akurasi dari beberapa algoritma parameter kualitas udara tersebut, komparasi data dilakukan secara kuantitatif dengan membandingkan hasil dari dua sensor satelit dengan periode perekaman yang sama. Penggunaan data dari dua citra satelit untuk membandingkan informasi kualitas udara diharapkan mampu meningkatkan efisien biaya, tenaga, maupun waktu.

\section{Metode}

Penelitian ini berlokasi di sekitar PLTU Cirebon yang berada di Kanci, Kabupaten Cirebon dengan area of interest (AOI) menyesuaikan jarak maksimum kedua pembangkit (Gambar 1). Penentuan jarak untuk melihat pengaruh pembangkit listrik terhadap kualitas udara tidak lebih dari 3.000 meter, karena semakin jauh dari sumber pencemar (point sources) menyebabkan konsentrasi polutan akan semakin berkurang (Alseroury, 2015). Pada kajian ini AOI dibatasi hanya sejauh 2.000 meter dari point sources. Data citra satelit penginderaan jauh yang digunakan untuk melihat perbedaan kualitas udara akibat pembangunan dan operasional PLTU Cirebon adalah Landsat series dengan data pembanding yang berasal dari Sentinel-2 MSS dan MODIS sebagaimana tersaji rinci pada Tabel 1 dengan mengambil waktu pengamatan yakni tahun 2004 dan 2019. Pengukuran lapangan secara in-situ tidak dapat dilakukan karena terkendala biaya, waktu, serta regulasi Pembatasan Sosial Berskala Besar (PSBB) akibat pandemi COVID-19 serta tidak memasukkan parameter kecepatan angin karena cenderung tidak memiliki pengaruh yang signifikan (Damara et al., 2017). Kajian ini merupakan lanjutan dari penelitian sebelumnya yang dilakukan oleh Nurhanifah et al. (2020). 


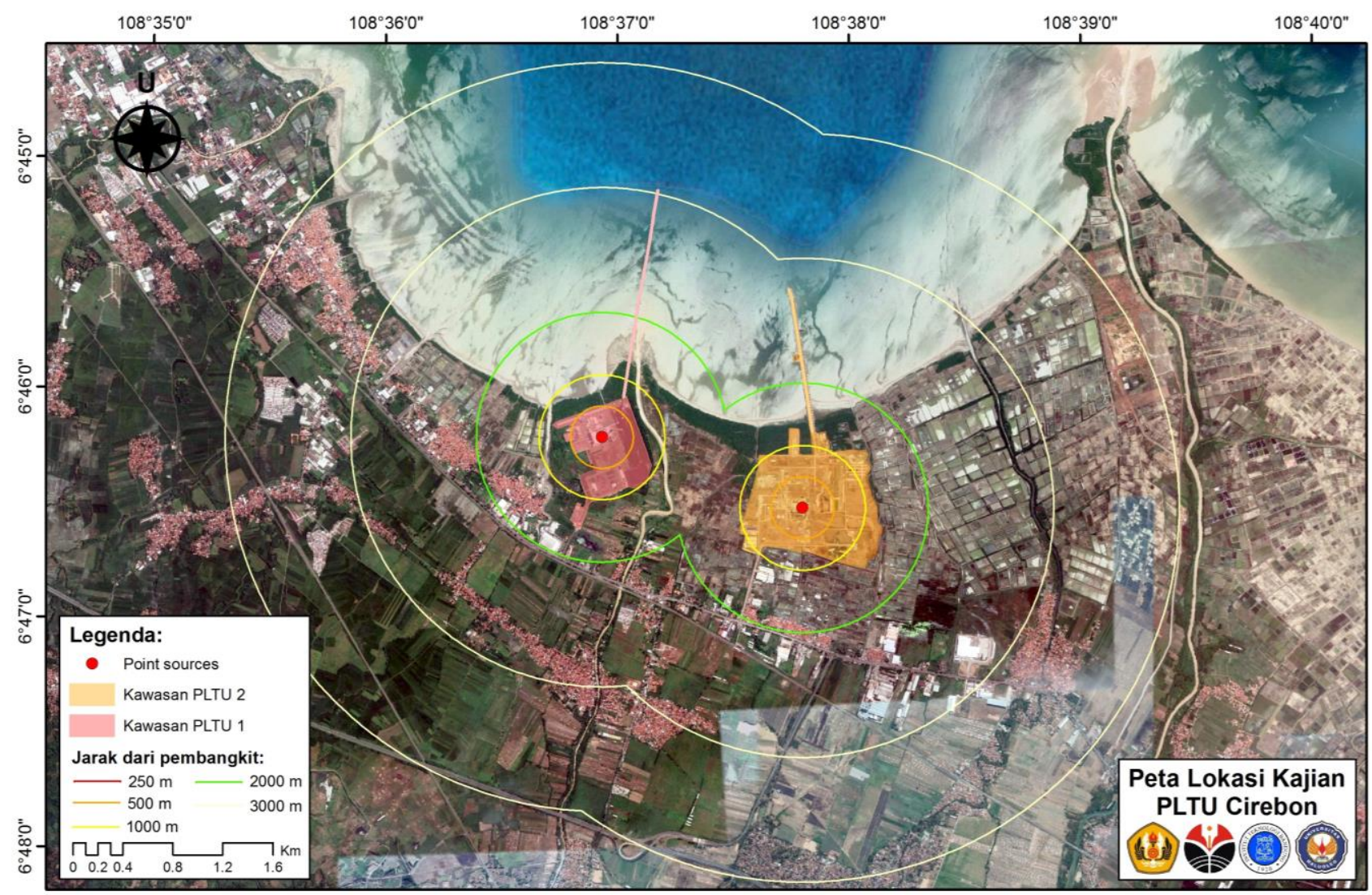

Gambar 1. Lokasi penelitian

\subsection{Algoritma kualitas udara}

Sebelum menerapkan algoritma kualitas, tiap band citra satelit penginderaan jauh harus melalui serangkaian tahapan koreksi secara geometrik, atmosferik, dan radiometrik (Young et al., 2017). Tujuan dari koreksi citra adalah untuk memperoleh nilai spektral yang terbebas dari gangguan medium udara, distorsi alat perekam, dan kesalahan dalam menampakkan objek. Setelah koreksi tersebut, citra satelit siap untuk dipotong sesuai AOI dan diolah menggunakan beragam algoritma kualitas udara seperti tersaji pada Tabel 2. Dari mulai tahap koreksi hingga memasukkan algoritma, informasi yang terkandung dalam metadata citra merupakan elemen fundamental agar menghasilkan nilai estimasi yang akurat (Korting et al., 2016; Baghdadi et al., 2018). Pada penelitian ini, digital number (DN) pada tiap kanal (band) citra satelit terlebih dahulu diubah menjadi nilai reflektansi BoA $(\rho)$ menggunakan metode DOS1. Khusus termal band, nilai suhu diperoleh dari brightness temperature yang kemudian diubah ke satuan celsius (lihat Hasan et al., 2014).

Tabel 1. Data penelitian

\begin{tabular}{lllll}
\hline Citra Satelit & & Resolusi Spasial & Tahun & Sumber \\
\hline Landsat-8 OLI & Band Red (B2) & $30 \mathrm{~m}$ & 2019 & Earth Explorer USGS \\
& Band Green (B3) & $30 \mathrm{~m}$ & & \\
& Band Blue (B4) & $30 \mathrm{~m}$ & & \\
& Band Thermal (B10 dan B11) & $100 \mathrm{~m}$ & & \\
& Band SWIR (B7) & $30 \mathrm{~m}$ & 2004 & Earth Explorer USGS \\
Landsat-7 & Band Red (B1) & $30 \mathrm{~m}$ & & \\
ETM & Band Green (B2) & $30 \mathrm{~m}$ & & \\
& Band Blue (B3) & $30 \mathrm{~m}$ & & \\
\multirow{5}{*}{ Sentinel-2 MSS } & Band Thermal (B6) & $60(30) \mathrm{m}$ & \multirow{2}{*}{ Copernicus ESA } \\
& Band SWIR (B7) & $30 \mathrm{~m}$ & & \\
& Band Red (B2) & $10 \mathrm{~m}$ & & \\
& Band Green (B3) & $10 \mathrm{~m}$ & & \\
MODIS & Band Blue (B4) & $10 \mathrm{~m}$ & 2019 & LAADS-DAAC NASA \\
\hline
\end{tabular}


Tabel 2. Algoritma kualitas udara

\begin{tabular}{|c|c|c|c|}
\hline Parameter & Citra Satelit & Algoritma & $\mathrm{R}^{2}$ \\
\hline \multirow[t]{4}{*}{$\mathrm{PM}_{10}$} & Landsat-8 OLI & Othman et al. (2010) & 0.79 \\
\hline & Landsat-7 ETM & $\mathrm{PM}_{10}=(96 \times \mathrm{BR} \rho)+(253 \times \mathrm{BG} \rho)-(194 \times \mathrm{BB} \rho)$ & \\
\hline & Sentinel-2 MSS & dimana PM10 merupakan partikulat aerosol $\left(\mu \mathrm{g} / \mathrm{m}^{3}\right), \mathrm{BR} \rho$ & \\
\hline & & $\begin{array}{l}\text { reflektansi BoA band merah (red), BG } \rho \text { reflektansi BoA band } \\
\text { hijau (green), dan BB } \rho \text { adalah reflektansi BoA band biru (blue). }\end{array}$ & \\
\hline \multirow[t]{5}{*}{$\mathrm{CO}$} & Landsat-8 OLI & Somvanshi et al. (2019) & 0.76 \\
\hline & Landsat-7 ETM & $\mathrm{CO}=83,659-(0,427 \times \mathrm{BG} \rho)+(0,22 * \times \mathrm{BB} \rho)-(0,461 \times \mathrm{SWIR} \rho)$ & \\
\hline & Sentinel-2 MSS & dimana CO merupakan karbon monoksida (mg/l), BG $\rho$ reflektansi & \\
\hline & & BoA band hijau (green), BB $\rho$ reflektansi BoA band biru (blue), dan & \\
\hline & & SWIRp reflektansi BoA short wave infrared band. & \\
\hline \multirow[t]{3}{*}{$\mathrm{SO}_{2}$} & Landsat-8 OLI & Hasan et al. (2014) & 0.52 \\
\hline & Landsat-7 ETM & $\mathrm{SO}_{2}=0,0117 \mathrm{~T}^{3}-0,3282 \mathrm{~T}^{2}+2,837 \mathrm{~T}-6,4733$ & \\
\hline & MODIS & $\begin{array}{l}\text { dimana } \mathrm{SO} 2 \text { merupakan kandungan sulfur dioksida di udara (ppm) } \\
\text { dan T nilai suhu pada thermal band (Celcius). }\end{array}$ & \\
\hline \multirow[t]{3}{*}{$\mathrm{NO}_{\mathrm{x}}$} & Landsat-8 OLI & Alseroury (2015) & 0.93 \\
\hline & Landsat-7 ETM & $\mathrm{NO}_{\mathrm{x}}=163,88+0,3908 \times \mathrm{T}$ & \\
\hline & MODIS & $\begin{array}{l}\text { dimana } \mathrm{NO}_{\mathrm{x}} \text { merupakan konsentrasi gas nitrogen oksida }\left(\mu \mathrm{g} / \mathrm{m}^{3}\right) \\
\text { dan nilai suhu pada thermal band (Celcius). }\end{array}$ & \\
\hline
\end{tabular}

\subsection{Analisis data}

Penelitian ini menggunakan pendekatan kuantitatif, dimana perubahan kualitas udara diketahui dari hasil analisis statistik. Validasi data dilakukan dengan membandingkan hasil dari dua citra satelit penginderaan jauh melalui uji korelasi Spearman-Rank (Persamaan 1) dalam mengukur satu parameter yang sama (Nurdian et al., 2020). Sementara itu, perubahan nilai beberapa parameter kualitas udara akibat pembangunan dan operasional PLTU Cirebon tidak hanya dianalisis secara deskriptif menggunakan informasi distribusi tendensi sentral, melainkan dianalisis secara inferensial melalui uji beda dan korelasi. Analisis perubahan kualitas udara menggunakan uji beda Mann-Whitney (U-Test) seperti yang ditunjukan pada Persamaan 2 dan 3 (Nurhanifah et al., 2020). Pemilihan kedua metode tersebut didasari atas asumsi bahwa data fenomena geografis memiliki pola distribusi yang beragam dalam satuan lokasi dan waktu tertentu (Setiawan et al., 2019). Adanya perubahan yang signifikan terhadap kualitas udara ditunjukkan jika U-hitung pada uji beda Mann-Whitney tidak lebih dari Utabel dan vice versa - saat $\mathrm{p}$-value tidak lebih dari 0,05 . Hal serupa juga berlaku dalam analisis korelasi Spearman-Rank, dimana data mengenai parameter kualitas udara dari dua sumber dinyatakan sama dan signifikan tatkala p-value tidak lebih dari 0,05. Rangkaian tahapan analisis tersaji pada Gambar 2 .

$\rho=\frac{6 \sum d_{i}^{2}}{\mathrm{n}\left(n^{2}-1\right)}$

dimana $\rho$ menunjukkan tingkat korelasi, $\mathrm{n}$ jumlah data yang diamati, and $\mathrm{d}$ merupakan difference value dari data yang disandingkan. Korelasi dinyatakan signifikan bila nilai $\rho$-hitung $>\rho$-tabel.

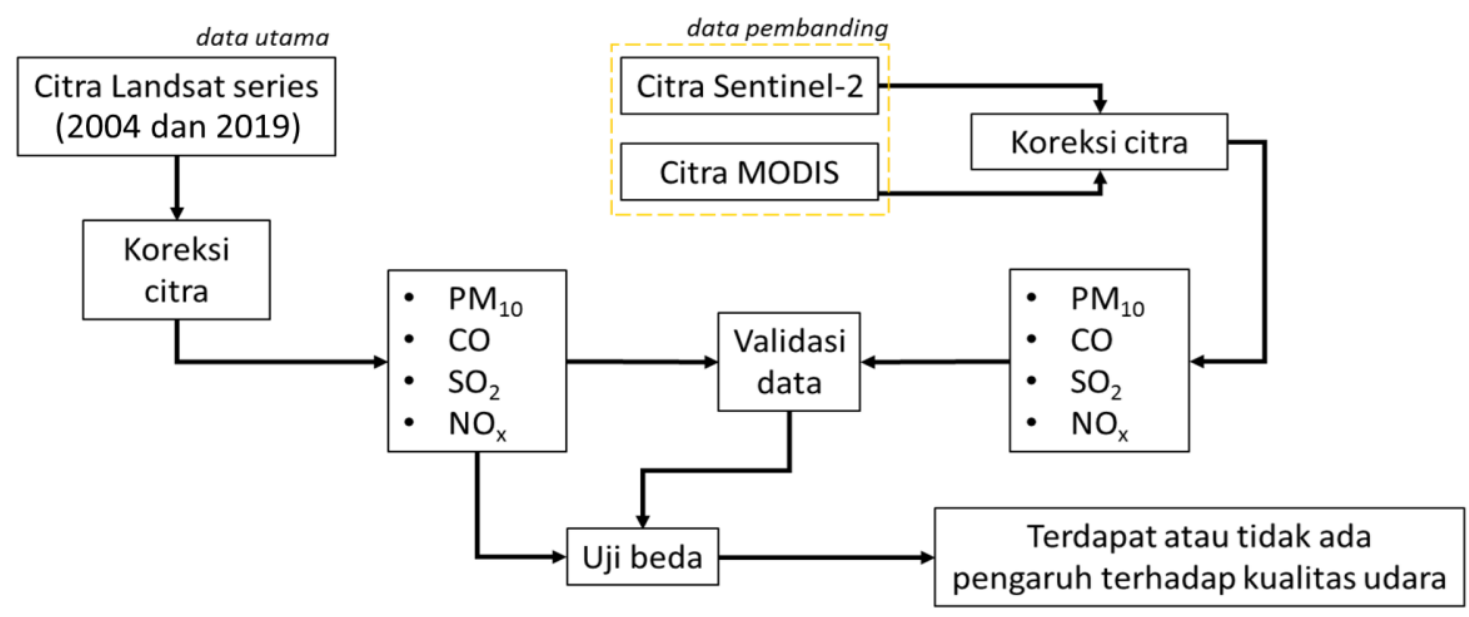

Gambar 2. Alur penelitian 
$U_{1}=n_{1} \times n_{2}+\left[\frac{n_{1}\left(n_{1}+1\right)}{2}\right]-\sum R_{1}$
$U_{2}=n_{1} \times n_{2}+\left[\frac{n_{2}\left(n_{2}+1\right)}{2}\right]-\sum R_{2}$

dimana $U$ merupakan nilai hasil uji Mann-Whitney, $n$ menunjukkan jumlah sampel untuk tiap dataset, dan $\mathrm{R}$ sebagai jumlah jenjang (ranking) setiap dataset. Perbedaan dinyatakan signifikan (ambil nilai terendahnya dari $\mathrm{U}_{1}$ atay $\mathrm{U}_{2}$ ) jika U-hitung $<$ U-tabel.

\section{Hasil dan Pembahasan}

Sebelum memaparkan dan membahas perubahan kualitas udara di sekitar PLTU Cirebon, validasi data merupakan langkah esensial agar menghasilkan informasi yang dapat dipertanggungjawabkan. Data parameter kualitas udara hasil pengolahan beragam algoritma dari citra Landsat-8 OLI terbukti menghasilkan informasi pola distribusi yang saling serupa dengan data dari citra Sentinel-2 MSS dan MODIS (Tabel 3). Komparasi algoritma kualitas udara yang berbasis band thermal umumnya menggunakan data pembanding dari citra satelit MODIS, sedangkan pada band lain dapat menggunakan pembanding dari citra satelit lain seperti Sentinel-2 MSS yang memiliki panjang gelombang dan nilai reflektansinya sama atau mendekati (Alvarez-Mendoza et al., 2019). Parameter PM10 dan CO memiliki korelasi lebih tinggi dibandingkan dengan parameter SO2 dan NOx, sehingga

Tabel 3. Validasi parameter kualitas udara

\begin{tabular}{llllll}
\hline Parameter & Data utama & Data pembanding & $\mathrm{r}$ & p-value & Keterangan \\
\hline $\mathrm{PM}_{10}$ & Landsat-8 OLI & Sentinel-2 MSS & 0,888 & 0,000 & Valid \\
$\mathrm{CO}$ & Landsat-8 OLI & Sentinel-2 MSS & 0,679 & 0,000 & Valid \\
$\mathrm{SO}_{2}$ & Landsat-8 OLI & MODIS & 0,349 & 0,034 & Valid \\
$\mathrm{NO}_{x}$ & Landsat-8 OLI & MODIS & 0,351 & 0,034 & Valid \\
\hline
\end{tabular}
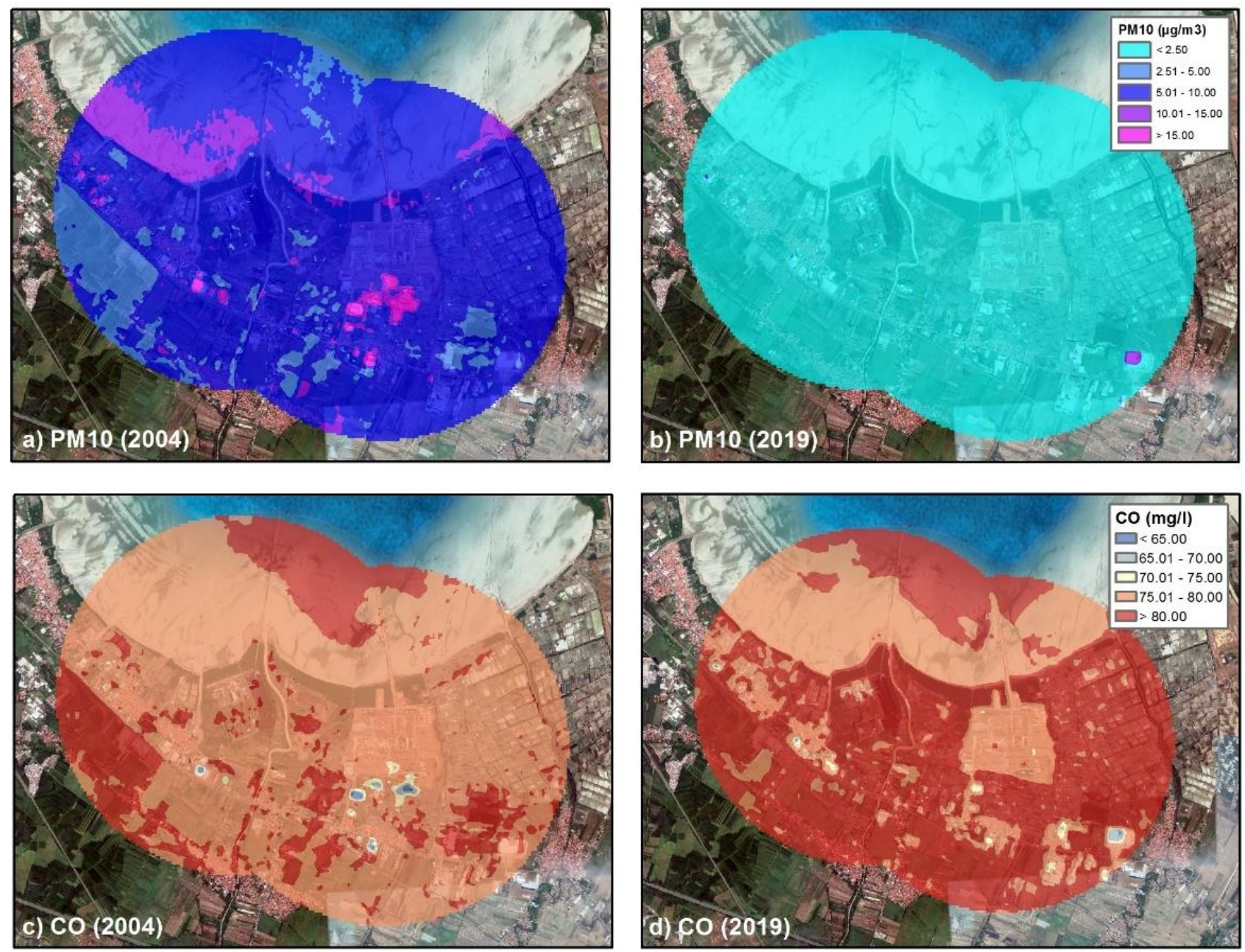

Gambar 3. Dinamika $\mathrm{PM}_{10}$ dan $\mathrm{CO}$ 
nilai $p$-value juga turut berbeda. Meski begitu, data dari pengolahan kualitas udara tersebut layak karena memiliki $p$-value kurang dari 0,05. Dengan menggunakan metode serupa, keempat algoritma tersebut berguna untuk mengestimasi kualitas udara pada periode sebelumnya saat kedua PLTU belum operasional. Penyajian hasil analisis dari beragam algoritma tersebut, ditumpang susunkan dengan ESRI World Imagery sebagai basemap sebagaimana tersaji pada Gambar 3 dan 4.

Pembangunan dan operasional PLTU merupakan wujud dinamika lanskap yang secara umum memiliki konsekuensi terhadap perubahan lingkungan di sekitarnya. Asumsi dasar dalam penelitian ini yakni berkurangnya lahan bervegetasi dan peningkatan aktivitas antropogenik berpotensi menurunkan kualitas udara, karena peningkatan polutan, gas buang, serta bahang (Lin et al., 2014; Yoo et al., 2015; Dede et al., 2019). Klaim kedua PLTU Cirebon sebagai salah satu pelopor pembangkit berbasis batubara yang menerapkan green technology terbukti benar setidaknya bila mengacu pada dinamika kualitas udara pada dua periode, walaupun berbanding terbalik dengan dampak terhadap kualitas perairan di sekitarnya melalui kenaikan sea surface temperature (SST) dan total suspended solid (TSS) yang disertai dengan penurunan kadar klorofil-A dan salinitas (Nurhanifah et al., 2020).

Kedua pembangkit tersebut hanya menaikkan kadar CO sebagaimana ditunjukkan pada Gambar 3c dan 3d. Pada radius $2000 \mathrm{~m}$ dari point sources, kadar CO rata-rata meningkat sebesar 1,25 mg/1 dengan rentang 59,3 hingga $82,92 \mathrm{mg} / 1$ pada tahun 2019. Peningkatan ini menunjukkan proses pembakaran kurang sempurna pada pembangkit akibat pemakaian batubara berkadar karbon rendah serta tidak

Tabel 4. Dinamika parameter kualitas udara

\begin{tabular}{lllllllllll}
\hline \multirow{2}{*}{ Parameter } & \multicolumn{2}{l}{ Tahun 2004} & \multicolumn{8}{c}{ Tahun 2019} \\
& Min & Maks & Rerata & SD & Rentang & Min & Maks & Rerata & SD & Rentang \\
\hline $\mathrm{PM}_{10}$ & 2,53 & 54,28 & 7,26 & 2,41 & 51,75 & 0,00 & 10,55 & 0,01 & 0,28 & 10,55 \\
$\mathrm{CO}$ & 51,99 & 82,35 & 78,89 & 1,58 & 30,36 & 59,30 & 82,92 & 80,14 & 1,35 & 23,61 \\
$\mathrm{SO}_{2}$ & 11,53 & 105,16 & 41,18 & 16,76 & 93,63 & 11,18 & 69,79 & 33,88 & 12,80 & 58,62 \\
$\mathrm{NO}_{\mathbf{x}}$ & 171,58 & 175,76 & 173,50 & 0,77 & 4,18 & 171,54 & 174,73 & 173,14 & 0,71 & 3,19 \\
\hline
\end{tabular}
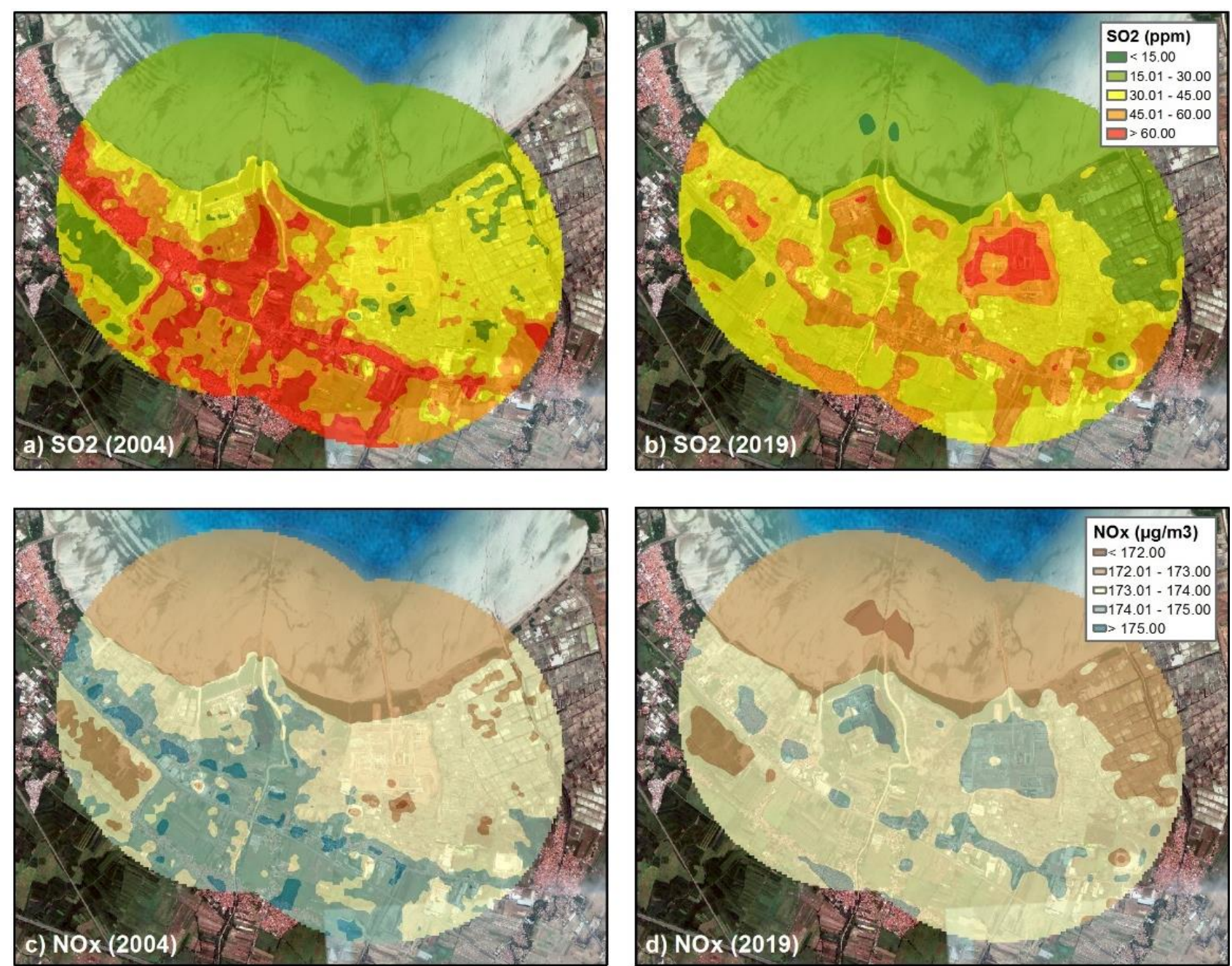

Gambar 4. Dinamika $\mathrm{SO}_{2}$ dan $\mathrm{NO}_{\mathrm{x}}$ 
Tabel 5. Uji beda parameter kualitas udara

\begin{tabular}{lllll}
\hline Parameter & Mann-Whitney U & Z & $p$-value & Keterangan \\
\hline PM $_{10}$ & 329818,000 & $-178,383$ & 0,000 & Ada perbedaan signifikan \\
CO & 1049536019,000 & $-96,134$ & 0,000 & Ada perbedaan signifikan \\
SO2 & 172872882,000 & $-42,200$ & 0,000 & Ada perbedaan signifikan \\
NOx & 172874284,000 & $-42,199$ & 0,000 & Ada perbedaan signifikan \\
\hline
\end{tabular}

Tabel 6. Korelasi antarparameter kualitas udara

\begin{tabular}{lrrrrrrrr}
\hline \multirow{2}{*}{ Parameter } & $\mathrm{PM}_{10}$ & \multicolumn{1}{c}{$\mathrm{CO}$} & \multicolumn{1}{c}{$\mathrm{SO}_{2}$} & $\mathrm{NO}_{\mathrm{x}}$ & $\mathrm{PM}_{10}$ & $\mathrm{CO}$ & $\mathrm{SO}_{2}$ & $\mathrm{NO}_{\mathrm{x}}$ \\
& 2004 & 2004 & 2004 & 2004 & 2019 & 2019 & 2019 & 2019 \\
\hline $\mathrm{PM}_{10} 2004$ & 1 & $-0,972$ & $-0,256$ & $-0,256$ & 0,173 & $-0,416$ & $-0,234$ & $-0,234$ \\
$\mathrm{CO} 2004$ & $-0,972$ & 1 & 0,166 & 0,166 & $-0,078$ & 0,393 & 0,144 & 0,144 \\
$\mathrm{SO}_{2} 2004$ & $-0,256$ & 0,166 & 1 & 1 & $-0,672$ & 0,244 & 0,814 & 0,814 \\
$\mathrm{NO}_{\mathbf{x}} 2004$ & $-0,256$ & 0,166 & 1 & 1 & $-0,672$ & 0,244 & 0,814 & 0,814 \\
$\mathrm{PM}_{10} 2019$ & 0,173 & $-0,078$ & $-0,672$ & $-0,672$ & 1 & $-0,205$ & $-0,797$ & $-0,797$ \\
$\mathrm{CO} 2019$ & $-0,416$ & 0,393 & 0,244 & 0,244 & $-0,205$ & 1 & 0,105 & 0,105 \\
$\mathrm{SO}_{2} 2019$ & $-0,234$ & 0,144 & 0,814 & 0,814 & $-0,797$ & 0,105 & 1 & 1 \\
$\mathrm{NO}_{\mathbf{x}} 2019$ & $-0,234$ & 0,144 & 0,814 & 0,814 & $-0,797$ & 0,105 & 1 & 1 \\
\hline
\end{tabular}

efektifnya sistem pengendalian emisi (scrubber) dalam mengeliminasi CO. Meski begitu, reaksi pembakaran sempurna dengan batubara berkadar karbon tinggi tetap akan menghasilkan gas $\mathrm{CO}_{2}-$ tetap menjadi faktor pencemaran. $\mathrm{CO}$ bersama dengan $\mathrm{SO}_{2}$ dan $\mathrm{NO}_{\mathrm{x}}$ dapat bereaksi dengan uap air di udara yang berpotensi menghasilkan senyawa bagi terbentuknya hujan asam serta dan membentuk lapisan gas rumah kaca yang dapat menghalangi pelepasan panas dari bumi ke luar angkasa (Astra, 2010).

Tabel 4 menunjukkan bahwa polutan selain CO mengalami kondisi berbeda, dimana operasional kedua PLTU tidak menaikkannya (lihat Gambar 3 dan 4). Penurunan terendah terjadi pada $\mathrm{NO}_{\mathrm{x}}$ yakni rata-rata sebesar $0.36 \mu \mathrm{g} / \mathrm{m}^{3}$, sedangkan penurunan tertinggi dialami oleh $\mathrm{PM}_{10}$ yakni rata-rata sebesar $7.25 \mu \mathrm{g} / \mathrm{m}^{3}$. Kadar $\mathrm{SO}_{2}$ mengalami penurunan sebesar 7,3 ppm dengan rentang 11,18 hingga 69,79 ppm. Dari segi distribusi spasial $\mathrm{SO}_{2}$ dan $\mathrm{NO}_{\mathrm{x}}$ berbeda dengan $\mathrm{PM}_{10}$ karena konsentrasi keduanya relatif lebih tinggi pada radius dekat dengan point sources yang menandakan sebagai salah satu sumber polutan. Penurunan gas buang pada wilayah yang lebih jauh dari point sources juga disebabkan oleh interaksi dengan senyawa gas lain atau berubah akibat reaksi fotokimia di udara menjadi gas polutan sekunder yang berbahaya sebagai pembentuk kabut (smog) (Ahmad, 2004; Gusnita, 2014). $\mathrm{NO}_{\mathrm{x}}$ dihasilkan dari pembakaran hidrokarbon bersamaan dengan keberadaan unsur $\mathrm{N}$ di udara. Selama pembakaran $\mathrm{N}$ yang berada di dalam bahan bakar bereaksi dengan oksigen membentuk $\mathrm{NO}_{\mathrm{x}}$ (Liun, 2002). Pembakaran batubara yang mengandung sulfur (mayoritas dalam senyawa $\mathrm{FeS}_{2}$ ) akan menghasilkan $\mathrm{SO}_{2}$ dan produk samping berupa $\mathrm{Fe}_{2} \mathrm{O}_{3}$ (Ahmad, 2004). Rendahnya kadar $\mathrm{SO}_{2}$ dan $\mathrm{NO}_{x}$ setelah operasional kedua PLTU menandakan sistem pengendalian emisi berjalan dengan baik.

Selain menganalisis dari tendensi sentral data kualitas udara, upaya untuk mengetahui signifikansi perubahan juga dilakukan melalui uji beda Mann-Whitney pada dataset tahun 2004 dan 2019. Analisis ini menunjukkan bahwa semua parameter kualitas udara mengalami perbedaan yang signifikan dengan p-value lebih rendah dari 0,05 seperti yang ditunjukkan pada Tabel 5. Perbedaan dalam konotasi positif ditunjukkan pada tiga parameter kualitas udara $\left(\mathrm{PM}_{10}, \mathrm{SO}_{2}\right.$, dan $\left.\mathrm{NO}_{\mathrm{x}}\right)$, sedangkan kondisi sebaliknya terjadi pada CO. Operasional PLTU Cirebon hanya mempengaruhi kenaikan serta mengubah distribusi kadar CO di udara, senyawa ini diketahui memiliki sifat yang sangat reaktif dan berdampak buruk bagi kesehatan manusia maupun hewan. Lokasi PLTU yang dikelilingi oleh lahan pertanian produktif dikhawatirkan berpengaruh terhadap produktivitas tanaman, karena peningkatan $\mathrm{CO}$ berpotensi mengganggu fiksasi nitrogen oleh bakteri perakaran dan bila teroksidasi juga dapat menjadi material penyebab hujan asam (Cameron \& Hales, 1996).

Pembakaran batubara maupun bahan menghasilkan beragam polutan dan panas yang bersumber dari saluran pembuangan yang sama. $\mathrm{PM}_{10}$ memiliki korelasi yang sangat rendah terhadap $\mathrm{SO}_{2}$ dan $\mathrm{NO}_{x}$ dari point-sources PLTU Cirebon (Tabel 6). $\mathrm{SO}_{2}$ dan $\mathrm{NO}_{x}$ memiliki sebaran yang lebih luas dan berasosiasi erat dengan suhu udara, terutama pada saat musim kemarau bila dibandingkan dengan partikulat (Tian et al., 2019). $\mathrm{PM}_{10}$ diketahui memiliki korelasi negatif dengan $\mathrm{CO}, \mathrm{SO}_{2}$, dan $\mathrm{NO}_{\mathrm{x}}$ dengan nilai koefisien yang berbeda. Konsentrasi $\mathrm{PM}_{10}$ pada wilayah dengan suhu dan kelembapan udara yang tinggi akan membentuk absorpsi dengan uap air yang menyebabkannya mudah jatuh ke permukaan baik ke tanah, bangunan, maupun tumbuhan (Kayes et al., 2019). 


\section{Kesimpulan}

Citra satelit penginderaan jauh seperti Landsat-8 OLI dan Landsat-7 ETM mampu mengestimasi perubahan kualitas udara di sekitar PLTU Cirebon, asalkan tetap divalidasi oleh instrumen lain misalnya dengan citra satelit Sentinel-2 MSS, serta MODIS. Dari keempat parameter kualitas udara, hanya $\mathrm{CO}$ yang mengalami peningkatan kadar yang signifikan sebesar $1,25 \mathrm{mg} / 1$ dengan disertai perluasan jangkauan spasialnya. Berbeda dengan CO, operasional PLTU Cirebon tidak meningkatkan kadar $\mathrm{PM}_{10}, \mathrm{SO}_{2}$, dan $\mathrm{NO}_{\mathrm{x}}$ bagi lingkungan sekitarnya yang menandakan upaya pengendalian emisi untuk ketiga polutan tersebut cukup berhasil dan terlokalisasi pada radius sekitar $500 \mathrm{~m}$, sehingga kadarnya menurun dalam radius $2000 \mathrm{~m}$. Berdasarkan nilai estimasi kualitas udara tersebut juga diketahui bahwa konsentrasi $\mathrm{PM}_{10}$ justru bertolak belakang dengan kadar emisi $\mathrm{PM}_{10}, \mathrm{SO}_{2}$, dan $\mathrm{NO}_{\mathrm{x}}$.

Sebagai peraih proper hijau dari pemerintah pada tahun 2019, operasional PLTU Cirebon seharusnya mampu menurunkan beban pencemaran secara signifikan guna mempertanggungjawabkan upaya pengelolaan dan peningkatan kualitas lingkungan hidup yang dilakukannya kepada publik (Leonard, 2020; KLHK, 2019). Anugerah proper hijau juga harus menjadi tantangan bagi pengelola ke depannya untuk meraih capaian pengelolaan lingkungan hidup yang lebih tinggi agar operasional PLTU Cirebon dapat memenuhi kriteria keberlanjutan ekologis, sosial, dan ekonomi.

\section{Referensi}

Ahmad, R. (2004). Kimia Lingkungan. Yogyakarta: Penerbit Andi.

Alseroury, F. A. (2015). The effect of pollutants on land surface temperature around power plan. International Journal of Mechanical and Production Engineering, 3, 17-21.

Alvarez-Mendoza, C. I., Teodoro, A. C., Torres, N., \& Vivanco, V. (2019). Assessment of remote sensing data to model PM10 Estimation in cities with a low number of air quality stations: A case of Study in Quito, Ecuador. Environtments, 6, 85.

Astra, I. M. (2010). Energi dan dampaknya terhadap lingkungan. Jurnal Meteorologi dan Geofisiska, 2, 1, $127-135$.

Baghdadi, N., Mallet, C., \& Zribi, M. (2018). QGIS and Generic Tools. New Jersey: ISTE \& John Wiley and Sons.

Cahyadi. (2011). Kajian teknis pembangkit listrik berbahan bakar fossil. JITE, 1, 12, 21-32.

Cahyadi (Ed.). (2015). PLTU Batubara Superkritikal yang Efisien. Jakarta: Balai Besar Teknologi Energi.

Cameron, L. M., \& Hales, B. J. (1996). CO inhibition of nitrogen fixation. Nitrogen Fixation: Fundamentals and Applications. Dordrecht: Springer.

Damara, D. Y., Wardhana, I. W., \& Sutrisno, E. (2017). Analisis dampak kualitas udara karbon monoksida (CO) di Sekitar Jl. Pemuda akibat kegiatan car free day menggunakan program Caline4 dan Surfer (studi kasus: Kota Semarang). Jurnal Teknik Lingkungan, 6, 1, 1-14.

Dede, M., Pramulatsih, G. P., Widiawaty, M. A., Ramadhan, Y. R., \& Ati, A. (2019). Dinamika suhu permukaan dan kerapatan vegetasi di Kota Cirebon. Jurnal Meteorologi Klimatologi dan Geofisika, $6,1,1-14$.

Dewanto, H. (2016). Analisis Dampak Lingkungan Hidup (ANDAL) Rencana Pembangunan dan Operasi Pembangkit Listrik Tenaga Uap (PLTU) Cirebon Kapasitas 1 X 1.000 Mw Kabupaten Cirebon Jawa Barat. Jakarta: PT. Cirebon Energi Prasarana.

Fernández-Pacheco, V. M., Lopez-Sanchez, C. A., Alvarez-Alvarez, E., Lopez, M. J. S., GarciaExpósito, L., Yudego, E. A., \& Carús-Candás, J. L. (2018). Estimation of PM10 distribution using Landsat5 and Landsat8 remote sensing. Proceedings, 2, 1438.

Gusnita, D. (2014). Pencemaran smog (asap kabut) sebagai dampak aktivitas antropogenik. Berita Dirgantara, 15, 2, 84-89.

Hasan, G., Al-Kubaisy, M. A., Nahhas, F. H., Ali, A. A., Othman, N., \& Hason, M. M. (2014). Sulfur dioxide (SO2) monitoring over Kirkuk City using remote sensing data. J Civil Environ Eng, 4, 155 .

ICED. (2018, Mei 30). Perencanaan elektrifikasi berbasis geospasial. Workshop Elektrifikasi Desa Melalui PLTS Terpusat. 30 Mei 2018, Kupang, Nusa Tenggara Timur.

ICEL. (2018). Peneliti Ingatkan Limbah PLTU Tingkatkan Suhu Laut. Internet sources URL https://icel.or.id/berita/peneliti-ingatkan-limbah-pltu-tingkatkan-suhu-laut/

Julianti, S. A., Jamaluddin, \& Amiruddin. (2018). Dampak keberadaan pembangkit listrik tenaga uap (PLTU) terhadap kondisi sosial ekonomi masyarakat di Kelurahan Panau Kecamatan Tawaili. Jurnal Elektronik Geo Tadulako Online 6, 2, 35-43. 
Kayes, I., Shahriar, S. A., Hasan, K., Akhter, M., Kabir, M. M., \& Salam, M. A. (2019). The relationships between meteorological parameters and air pollutants in an urban environment. Global J. Environ. Sci. Manage., 5, 3, 265-278.

KLHK. (2019). Program Penilaian Peringkat Kinerja Perusahaan dalam Pengelolaan Lingkungan Hidup 2019. Jakarta: Sekretariat Proper KLHK RI.

Korting, T., Namikawa, L. M., Fonseca, L. M. G., \& Felgueiras, C. A. (2016). How to effectively obtain metadata from remote sensing big data?. In Proceeding of GEOBIA 2016: Solutions and Synergies. Enschede: University of Twente

Leonard, L. (2020). Cirebon Power Raih Proper Hijau 2019 dari KLHK. Internet sources URL https://ekonomi.bisnis.com/read/20200108/44/1188341/cirebon-power-raih-proper-hijau-201 9-dari-klhk.

Lin, C. A., Chen, Y. C., Liu, C. Y., Chen, W. T., Seinfeld, J. H., \& Cjou, C. C. K. (2019). Satellitederived correlation of SO2, NO2, and aerosol optical depth with meteorological conditions over East Asia from 2005 to 2015. Remote Sensing, 11, 1738.

Lin, G., Fu, J., Jiang, D., Hu, W., Dong, D., Huang, Y., \& Zhao. (2014). Spatio-temporal variation of PM2.5 concentrations and their relationship with geographic and socioeconomic factors in China. Int. J. Environ. Res. Public Health, 11, 1, 173-186.

Liun, E. (2002). Biaya eksternal PLTU Batubara Suralaya. Jurnal Pengembangan Energi Nuklir, 4, 1, $27-$ 42.

Martin, R. V. (2008). Satellite remote sensing of surface air quality. Atmospheric Environment, 42, 78237843.

Matharaarachchi, S., Manawadu, L., \& Gunatilake, J. (2016). Evaluation of urban air pollution distribution in the Colombo Municipal Council Area, Sri Lanka. In Geostatistical and Geospatial Approaches for the Characterization of Natural Resources in the Environment: Challenges, Processes and Strategies. New Delhi: Springer.

Muhaimin, Sugiharto, E., dan Suratman, A. (2016). Air pollution simulation from Cirebon power plant activity. Eksakta: Jurnal Imu-Ilmu MIPA, 15, 1, 14-22.

Nguyen, T. T. N., Bui, H. Q., Pham, H. V., Luu, H. V., Man, C. D., Pham, H. N., \& Le, H. T. (2015). Particulate matter concentration mapping from MODIS satellite data: A Vietnamese case study. Environmental Research Letters, 10, 9, 095016.

Nicolantonio, W. D., Cacciari, A., \& Tomasi, C. (2009). Particulate matter at surface: Northern Italy Monitoring Based on satellite remote sensing, meteorological fields, and in-situ samplings. Selected Topics in Applied Earth Observations and Remote Sensing, 2, 284-292.

Nurdian, W., Dede, M., Widiawaty, M. A., Ramadhan, Y. R., \& Purnama, Y. (2020). Pemanfaatan sensor mikro DHT11-Arduino untuk monitoring suhu dan kelembaban udara. Prosiding Seminar Nasional Tahunan Ilmu Lingkungan Universitas Padjadjaran Tahun 2019. Bandung: Unpad Press.

Nurhanifah, Widiawaty, M. A., \& Ismail, A. (2020). Pengaruh PLTU Rawaurip terhadap kualitas perairan Teluk Mundu, Kabupaten Cirebon. In Naskah Finalis KTI Geosac 2020. Bandung: Unpublished.

Nurhasanah, T. N. (2017). Pencemaran Udara Akibat Penggunaan Batubara sebagai Sumber Energi Pembangkit Listrik Tenaga Uap (PLTU) Kecamatan Astanajapura Kabupaten Cirebon di Hubungkan dengan Undang-Undang Nomor 32 Tahun 2009 Tentang Perlindungan dan Pengelolaan Lingkungan Hidup. Undergraduate thesis, Faculty of Law, Universitas Pasundan.

Quina, M., \& Erou, A. (2018). Memastikan pemenuhan kewajiban pengendalian pencemaran udara STB: PLTU batubara. In Seri Lembar Informasi Pencemaran Udara. Jakarta: YLBH, WALHI, Greenpeace, \& ICEL.

Setiawan, I., Dede, M., Sugandi, D., \& Widiawaty, M. A. (2019). Investigating urban crime pattern and accessibility using geographic information system in Bandung City. KnE Social Sciences, 3, $21,535-548$.

Somvanshi, S. S., Vashisht, A., Chandra, U. \& Kaushik, G. (2019). Delhi air pollution modeling using remote sensing technique. In Handbook of Environmental Materials Management. Basel: Springer Nature Switzerland AG.

Suriamiharja, D. A. (2008). Analogi hukum termodinamika dalam interaksi ekonomi dan lingkungan. an article in Konferensi BKPSL. 6 - 8th August 2008, Manado, Sulawesi Utara, Indonesia. 
Tian, Y., Tao, X., \& Chen, L. (2019). Analysis of spatial and seasonal distributions of air pollutants by incorporating urban morphological characteristics. Computers, Environment and Urban Systems, $75,35-48$.

Untsa, Q. D. (2017). Mekanisme Penunjukan Langsung Pada Pembangunan Infrastruktur Ketenagalistrikan dalam Perspektif Hukum Persaingan Usaha. Master Thesis, Faculty of Law, Universitas Gajah Mada.

Wald, L., Basly, L., \& Baleynaud, J. M. (1998). Satellite data for the air pollution mapping. An article in 18th EARSeL Symposium on Operational Remote Sensing for Sustainable Development. May 1998, Enschede, Netherlands.

Yoo, J. M., Jeong, M. J., Kim, D., Stockwell, W. R., Yang, J. H., Shin, H. W., Lee, M. I., Song, C. K., \& Lee, S. D. (2015). Spatiotemporal variations of air pollutants (O3, NO2, SO2, CO, PM10, and VOCs) with land-use types. Atmos. Chem. Phys, 15, 10857-10885.

Young, N. E., Anderson, R. S., Chignell, S. M., Voorster, A. G., Lawrence, R., \& Evangelista, P. H. (2017). A survival guide to Landsat preprocessing. Ecology, 98, 4, 920-932. 